\title{
ANALYTICAL RESULTS OF OUTPUT RESTRICTION DUE TO THE VOLTAGE INCREASING OF POWER DISTRIBUTION LINE IN GRID-CONNECTED CLUSTERED PV SYSTEMS
}

\author{
Yuzuru Ueda ${ }^{1}$, Takashi Oozeki ${ }^{1}$, Kosuke Kurokawa $^{1}$, Takamitsu Itou $^{2}$, Kiyoyuki Kitamura ${ }^{2}$, Yusuke Miyamoto ${ }^{3}$, Masaharu \\ Yokota $^{3}$, Hiroyuki Sugihara ${ }^{3}$, Shogo Nishikawa ${ }^{4}$ \\ ${ }^{1}$ Tokyo University of Agriculture and Technology, 2-24-16 Naka-cho,Koganei,Tokyo 184-8588, Japan \\ ${ }^{2}$ MEIDENSHA CORPORATION, Riverside Building, 36-2, Nihonbashi Hakozakicho, Chuo-Ku, Tokyo 103-8515, Japan \\ ${ }^{3}$ Kandenko co., Itd., 4-8-33 Shibaura Minato-ku Tokyo 108-8533, Japan \\ ${ }^{4}$ Nihon University, 1-8-14 Kanda Surugadai Chiyoda-ku Tokyo 101-8308, Japan
}

\begin{abstract}
Output restriction to prevent over voltage of power distribution line is one of the concerns for grid-connected clustered PV systems. To investigate the behavior of clustered PV systems, "Demonstrative research on clustered PV systems" has being conducted from December, 2002 in Gunma, Japan. More than 200 residential PV systems are already installed in demonstrative research area. Operation point of array output is estimated using minutely averages of collected data. The method to quantify loss due to output restriction is developed in this study.
\end{abstract}

\section{INTRODUCTION}

Reverse power flow from the grid-connected photovoltaic (PV) systems will increase the power distribution line's voltage. In the case that large numbers of residential PV systems are connected to the power grid within a small area, this situation called "clustered", amount of delta- voltage will be higher than the standalone PV systems. To maintain a power distribution line's voltage, Japanese commercial PV system's power conditioning subsystems (PCS) is monitoring its own output voltage. If it is higher than the specification, PCS will automatically reduce its output to prevent the overvoltage of the power distribution line. Because of this function, PV system's output will be restricted even if PV array is receiving enough solar irradiance. Since the clustered PV systems increase power distribution line's voltage more, output loss due to this restriction is one of the concerns for clustered PV systems.

\section{OVERVIEW OF DEMONSTRATIVE RESEARCH}

To investigate the behavior of the clustered PV systems, and develop the new technology to avoid the output restriction of the clustered PV systems, "Demonstrative research on clustered PV systems" (NEDO) has being conducted from December, 2002 in Gunma, Japan. [1] More than 200 residential PV systems are already installed on top of the roofs and connected to the power grid in less than $1 \mathrm{~km}^{2}$ area. To avoid the output restriction, battery integrated residential PV systems are developed in this research. Installation of these batteries will start from year 2005. Thus all of the installed PV systems are standard commercial PV system which does not have a battery. (As of Dec, 2004)

\section{MEASUREMENT EQUIPMENTS}

All of the installed PV systems are equipped with measurement system which is shown in Figure 1. (Array temperature and solar irradiance are optional) Voltages, currents and phases are being measured every second at the points of PV array output, PCS output and connecting point to the power grid. Measurement items are shown in Table 1. PCS-B in Fig. 1 is a PCS for battery. Voltage, current and temperature of battery will be measured. Solar irradiance, ambient temperature, wind direction and wind speed are also measured every second at the meteorological stations which are shown in Figure 2. Daily, hourly and minutely averages of the original data are available in the database.

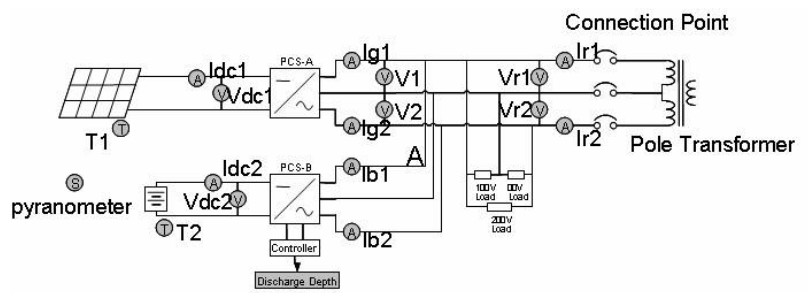

Figure 1: Schematic view of individual measurement system

Table 1: Measurement items

\begin{tabular}{|l|l|}
\hline Items & measurement \\
\hline Connection point Current (Ir1, Ir2) & AC Current (rms), Phase \\
\hline Connection point Voltage (Vr1, Vr2) & AC Voltage (rms), Phase \\
\hline PCS-A Current (PV array) (Ig1, Ig2) & AC Current (rms), Phase \\
\hline PCS-A Voltage (PV array) (V1, V2) & AC Voltage (rms), Phase \\
\hline PCS-B Current (Battery) (Ib1, Ib2) & AC Current (rms), Phase \\
\hline PV array current (Idc1) & DC Current \\
\hline PV array Voltage (Vdc1) & DC Voltage \\
\hline Battery Current (Idc2) & DC Current \\
\hline Battery Voltage (Vdc2) & DC Voltage \\
\hline PV temperature T1 & Temperature \\
\hline Battery temperature T2 & Temperature \\
\hline
\end{tabular}




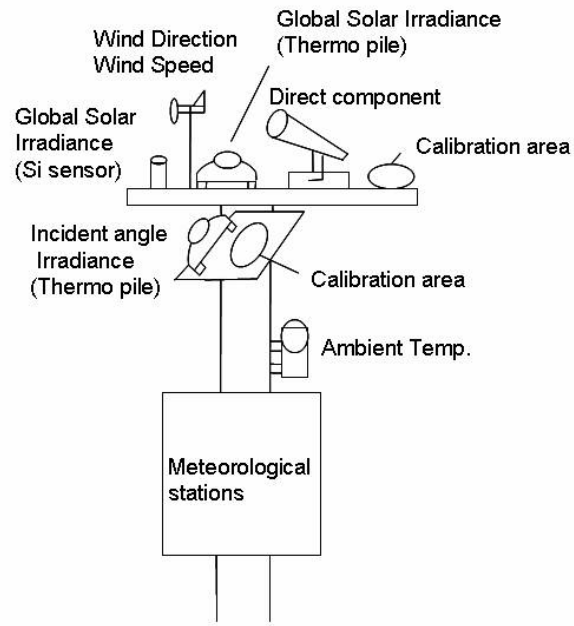

Figure 2: Schematic view of meteorological stations

\section{METHODS}

\section{Output loss of PV systems}

Figure 3 describes loss factors of PV systems and its flow. At first, Input energy will be reduced by shading, incident angle, dirt on module surface and degradation of module. These losses will occur before the energy conversion. During the energy conversion, efficiency will be affected by module temperature. If it is higher than $25 \mathrm{deg}$ C, typical Si solar cell's efficiency is lower than the standard efficiency which is defined at 25degC. Spectral mismatch between solar irradiance and solar cell is also the factor of losses. Operation point is another factor of loss during energy conversion. Because of the solar cell's I-V characteristics, the maximum power point $\left(P_{\max }\right)$ on the $\mathrm{P}-\mathrm{V}$ curve is not the same at the different input solar irradiance. To improve the performance of PV systems, maximum power point tracker (MPPT) of PCS is adjusting its operation point to keep $P_{\max }$. However, if the fluctuation of solar irradiance or that of the load is too fast, MPPT can not track $P_{\text {max }}$. This mismatch between $P_{\max }$ and operation point is one of the loss factors.

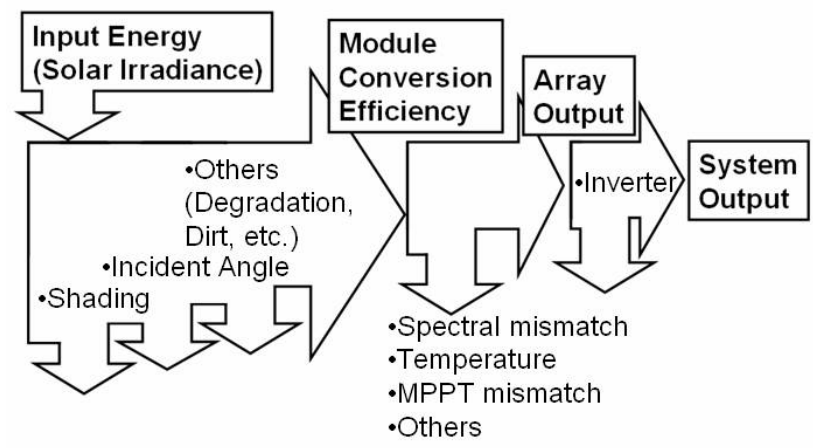

Figure 3: Loss factors of PV systems

In the case that PCS need to restrict its output to prevent over voltage of power distribution line, PCS will shift the operation point from $\mathrm{P}_{\max }$ to bad operation point toward the open-circuit voltage (Voc) in order to reduce its output.

Finally the power will be lost during inversion from $D C$ to $A C$ at the PCS.

\section{Performance and loss analysis}

Overall system performance was evaluated by performance ratio which is defined as a ratio of expected standard output during the evaluation period and actual output from the PV system. To investigate the output restriction, PV array output and solar irradiance were plotted to the scatter diagrams. Figure 4 and Figure 5 are results of the evaluation system using hourly averages and minutely averages of measured data respectively. This system's PCS was set to constant output mode so PCS's output would be constant power during the output restriction. Results of constant output control were observed in Fig. 5 while Fig. 4 did not show any sign of constant output control. Thus minutely averages of the data were used in this analysis.

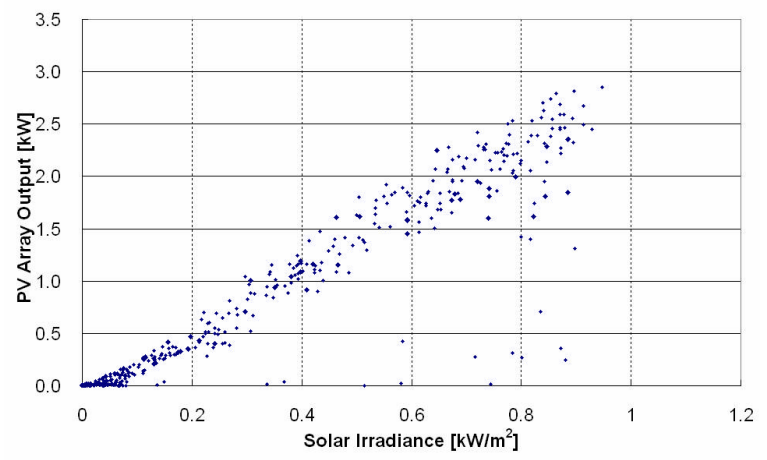

Figure 4: Scatter diagram using hourly averages of data

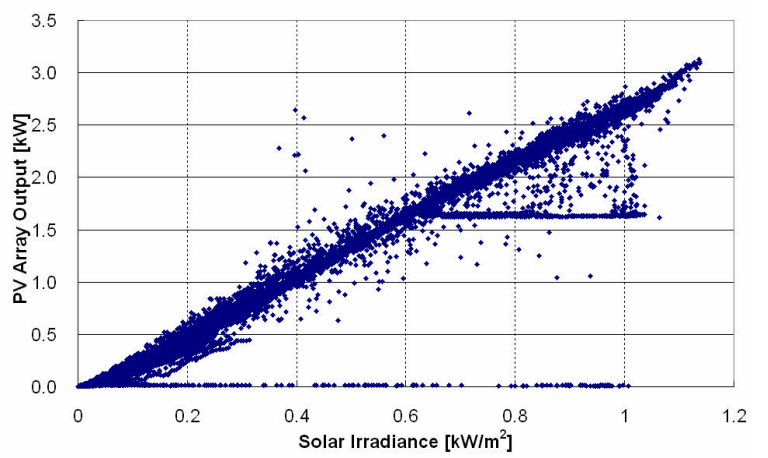

Figure 5: Scatter diagram using minutely averages of data

Array output voltage and current were mainly used to estimate operation point on the I-V curve to detect output restriction. Output voltage and array temperature were plotted into the scatter diagram as shown in Figure 6. Locus of $P_{\max }$ can be calculated by equation (1). Current and solar irradiance were also plotted into the scatter diagram as shown in Figure 7. Range of $\mathrm{IP}_{\max }$ was defined as equation (2). If the output voltage is above the locus in Fig. 6 and output current is below the range of Fig. 7, that 
data point can be assumed as the data that is in restriction mode. (Figure 8)

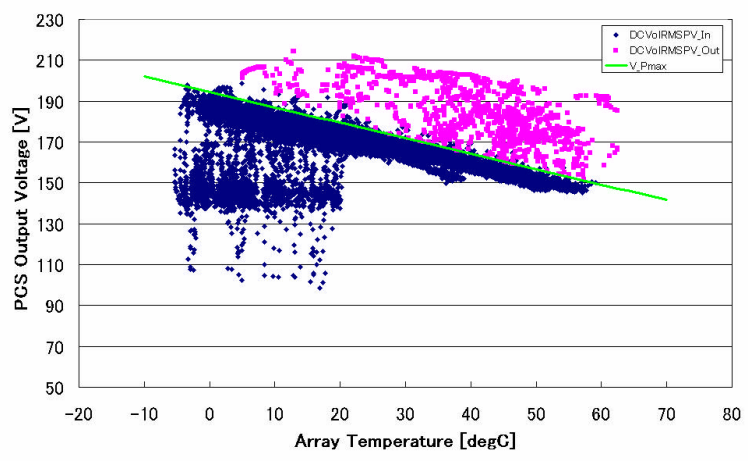

Figure 6: Scatter diagram of array output voltage and array temperature. Line is locus of $V_{P \max }$ which was calculated by equation (1)

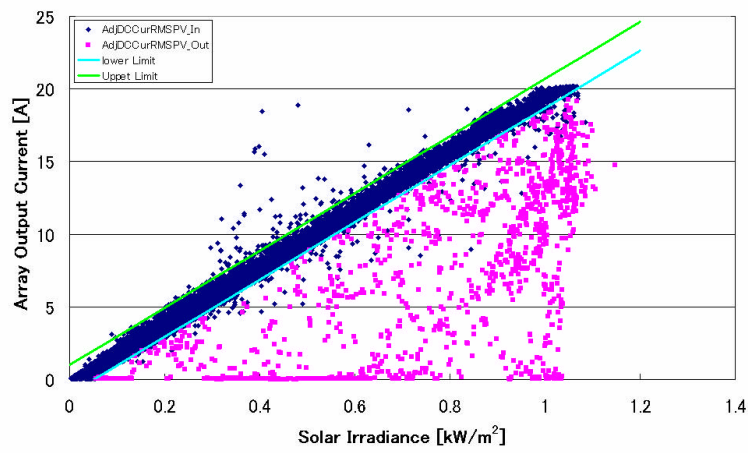

Figure 7: Scatter diagram of array output current and solar irradiance. Area between the two lines is the area of $I_{P \max }$ which was calculated by equation (2)

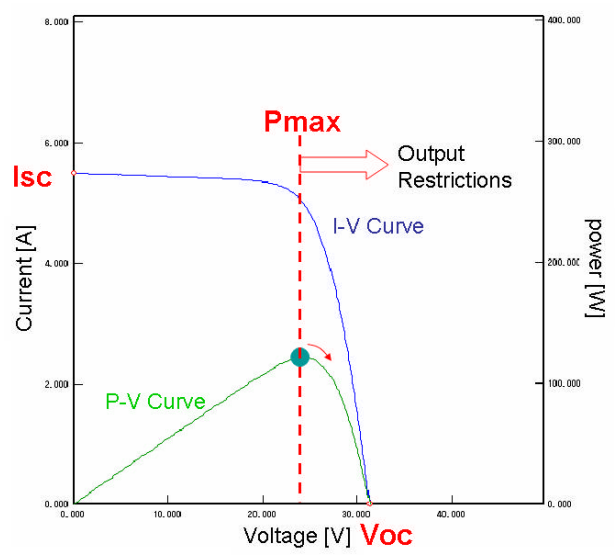

Figure 8: Example of $\mathrm{I}-\mathrm{V}$ curve and $\mathrm{P}-\mathrm{V}$ curve. Operation point at the right side of $P_{\max }$ line can be assumed as the data that is in restriction mode.

$$
\mathrm{Y}=\beta \times \mathrm{N}_{\text {series }} \times \mathrm{X}+\left(\mathrm{V}_{\mathrm{P}_{\max }} \times \mathrm{N}_{\text {series }}+\beta \times \mathrm{N}_{\text {series }} \times(-25)\right)+\mathrm{C}
$$

where

$\mathrm{Y}=\mathrm{PCS}$ output voltage, $\mathrm{X}=$ Array temperature $\mathrm{V}_{\mathrm{Pmax}}=$ Module's standard output voltage at $\mathrm{P}_{\max }[\mathrm{V}]$
$\mathrm{N}_{\text {series }}=$ Number of modules connected series

$\mathrm{B}=$ Temperature coefficient of voltage [V/degC] $\mathrm{C}=$ Constant value which was obtained as the average of 10 sites $(=1.0)$.

$$
\mathrm{Y}=\mathrm{I}_{\mathrm{P}_{\max }} \times \mathrm{N}_{\text {parallel }} \times \mathrm{C}_{\text {loss }} \times \mathrm{X} \pm \mathrm{C}_{\text {range }}
$$

where

$\mathrm{Y}=$ Array output current, $\mathrm{X}=$ Solar irradiance

$I_{P \max }=$ Module's standard output current at $P_{\max }[A]$

$\mathrm{N}_{\text {parallel }}=$ Number of string connected parallel

$\mathrm{C}_{\text {loss }}=$ Constant value which was obtained as the average of 10 sites $(=0.95)$

$\mathrm{C}_{\text {range }}=$ Range for $I_{P \max }(= \pm 1)$

\section{RESULTS AND DISCUSSIONS}

Analyzed results of site A are shown in Figures 9, 10 and 11. Data were collected from Mar-15 to Apr-19, 2004. This site was one of the worst cases in terms of the output restrictions during this evaluation period. Site A does not have any shading loss according to the field research so shading loss was not considered in these results. Loss due to incident angle was normally less than $1 \%$ of performance ratio [2] so this was also not considered in this analysis. Temperature of each data points were converted into the standard condition (25degC) using actual measured array temperature and module's temperature coefficient. Output loss due to temperature increasing was calculated from these conversion results. Capacity of PCS is sometimes smaller than that of array's to reduce the initial cost of installation. Loss due to PCS capacity shortage was calculated based on the size of PCS. Since there is some distance between meteorological stations and PV array (normally less than $200 \mathrm{~m}$ ), shadow of moving clouds block the sunlight either pyrheliometer or PV array. This situation causes either gain or loss of PV output. And these variations were classified as the fluctuation loss including MPPT mismatch loss. Power of PCS was sometimes turned off for maintenance purpose. Array outputs during these poweroff periods were classified as loss due to PCS off. IP Line means ideal performance during the evaluation period. If there is no loss for the data point, output will be on this line, and this line is almost the same as standard output because the system is very new and no serious dirt or degradation are expected.

As shown in Figure 9, performance ratio of this system during the evaluation period was $68.1 \%$. This means $31.9 \%$ of expected output was lost in some reasons. Loss due to array temperature increasing was $1.4 \%$. (Average ambient temperature was around ten degree Celsius during the evaluation period in Gunma) Actual PCS output was not measured during this evaluation period, however, after August, 2004, actual PSC output was measured and efficiency of the PCS was obtained. PCS output for this analysis was calculated using obtained efficiency. $13.3 \%$ of expected output was lost due to the output restriction. Figure 11 shows daily loss analysis results of site A. $73 \%$ of expected output was lost due to the output restriction on Mar-28. Loss due to 
PCS off was large in Apr-8 and Apr-13 because PCS was powered off during these days for maintenance purpose.

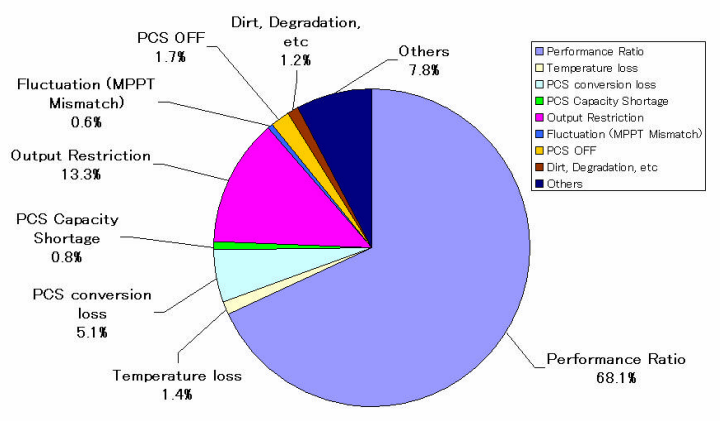

Figure 9: Performance ratio and loss analysis results of site A during Mar-15 to Apr-19, 2004.

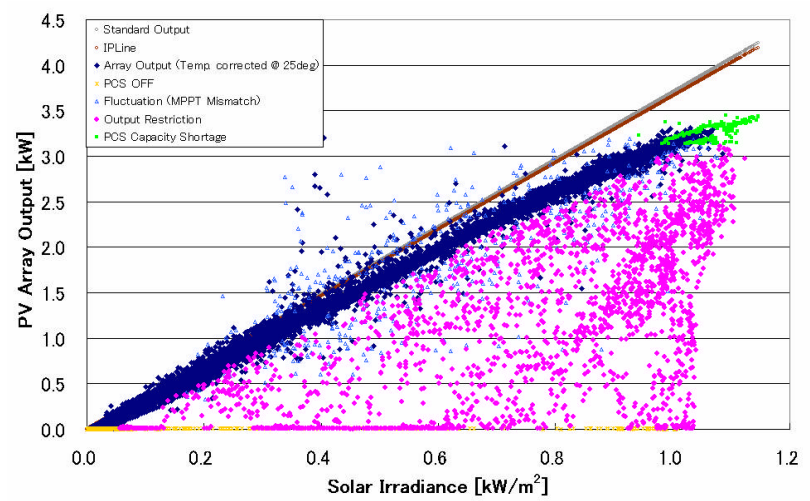

Figure 10: Scatter diagram of array output and solar irradiance. Each data points are minutely averages of the original data. All the data points were classified by the loss factors.

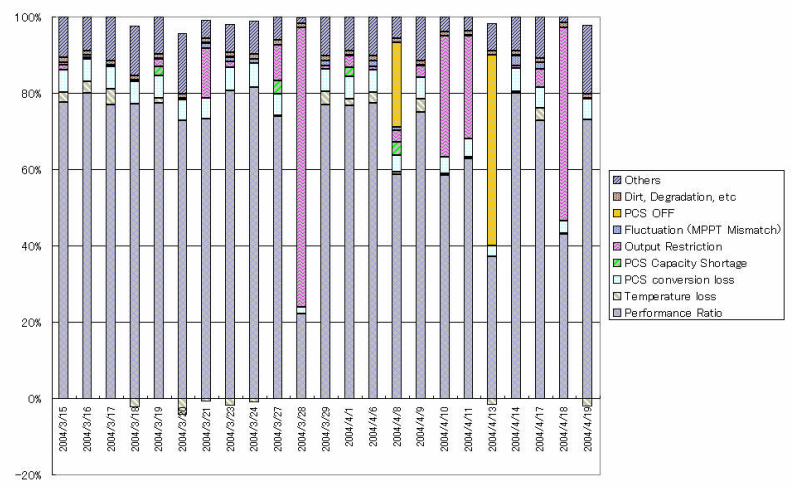

Figure 11: Daily analysis results of site A during Mar-15 to Apr-19, 2004. 73\% of expected output was lost due to the output restriction on Mar-28.

Figure 12 shows minutely averages of solar irradiance, array output and PCS output voltage on March 28. Output voltage of PCS was around the upper limit of the power distribution line $(107 \mathrm{~V})$ so output was restricted through a day. Array output was almost zero between 8:00 to 9:00 and 14:00 to $16: 00$ because voltage of PCS output exceeds the upper limit of the power grid. However, actual power distribution line's voltage might not be the same as the PCS output voltage because actual power line's voltage will be varied by load.

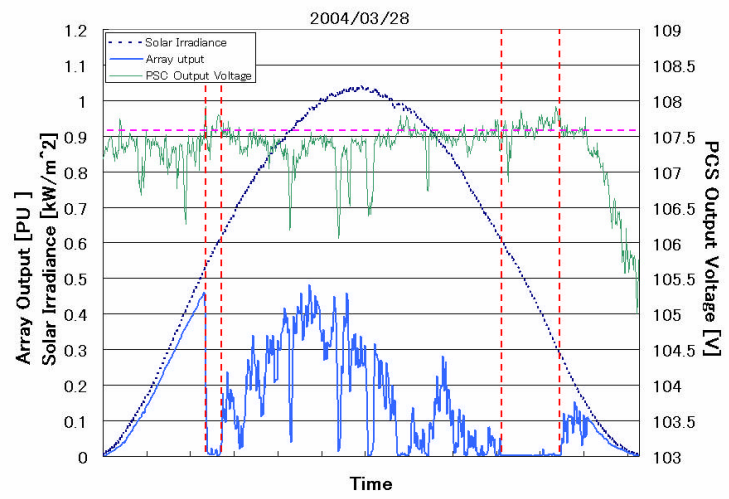

Figure 12: Solar irradiance, array output and PCS output voltage on March 28. Output voltage is around the upper limit of the power grid so output was restricted through a day.

\section{CONCLUSIONS}

Analysis method for output restriction was developed in this study. This method can quantify the amount of output power loss due to the output restriction effectively. $73 \%$ of expected output was lost in worst case on daily basis. More than $90 \%$ of expected outputs were lost in worst case on minutely basis.

Demonstrative research on clustered PV systems will be continued until 2008. Battery integrated PV systems will be installed in next year. Detailed loss analysis for both standard PV systems and battery integrated PV systems will be performed based on this analysis method.

\section{ACKNOWLEDGEMENT}

Demonstrative research on clustered PV systems is a project of New Energy and Industrial Technology Development Organization (NEDO). The authors would like to acknowledge the financial support of NEDO and cooperative discussions with project members.

\section{REFERENCES}

[1] Shogo Nishikawa, Kazuhiko Kato, "DEMONSTRATIVE RESEARCH ON GRID-INTERCONNECTION OF CLUSTERED PHOTOVOLTAIC POWER GENERATION SYSTEMS", 3rd World Conference on Photovoltaic Energy Conversion, 2003, 8LN-C-03

[2] Takashi Oozeki et al., "The Evaluation Method of PV Systems", $12^{\text {th }}$ International Photovoltaic Science and Engineering Conference, 2001, P-185 